\title{
Nurse Manager's Attitudes and Preparedness Towards Effective Delegation in a Tertiary Care Public Hospital Lahore
}

\author{
Hafiza Anam Khadim*, Afsar Ali, Muhammad Salman Ijaz, Naseem Rooman \\ National College of Nursing, The University of Lahore, Lahore, Pakistan.
}

\begin{abstract}
Background: Delegation is among the oldest concepts associated to professional and clinical nursing. With the rapid changes in the profession, delegation is becoming more important for nurse leaders and managers. It is highly expected from the manager nurses to effectively organize tasks of other health care workers and supervise them successfully. The ability of a nurse manager is very Crucial to the success of delegation among nurses.
\end{abstract}

Objective: The main purpose of this study was, to assess The Nurse Managers' attitudes and Preparedness towards Effective Delegation in a Tertiary Care Public Hospital Lahore.

Method: A cross sectional descriptive survey was performed to assess the knowledge of nurse managers, (nursing supervisors, head nurses, and charge nurses) working at Punjab Institute of Cardiology \& Services Hospital Lahore. A convenient sample of $\mathrm{n}=150 \mathrm{was}$ used to collect the data from both hospitals, (85) from PIC and (65) from SHL. A structured adopted questionnaire was used to collect data and study's questionnaire, Data used in this study consisted of two main scales as well as demographic data sheets were collected. The data was analyzed on SPSS version 21.

Results: The results of this study reveals that majority of the participants, $88 \%$ were having positive attitude towards delegation who scored 35 or above on a scale of 55 total score, while $12 \%$ had negative attitude who scored below 35 on attitude scale of 55 . The results of this study indicate that $82.67 \%$ participants had good preparedness, who scored 75 or above in a total of 100 score, while remaining $17.3 \%$ scored less than 75 and had poor preparedness.

Conclusion: Overall attitude and preparedness was positive and good towards the delegation among nurses

Keywords: Attitude, Preparedness, Nurse Managers, Delegation, Public hospital, Clinical nursing.

\section{INTRODUCTION}

It is the primary responsibility of registered Nurses to effectively distribute the scarce health care facilities and resources. Nurses should make it sure that every patient in bed is receiving the needed nursing care. It is believed that still many nurses are ignoring their role of justified distributer and care giver [1].

The work of nurses in the 21 st century has become more complex because of the complicated nature of health care system. The nurses along with their basic role of care giver also occupy different other roles such as advocate of their clients, care coordinator, educator for clients and families, and supervisor of the required nursing services [2].

For an effective process of delegation and to have competent delegators, the American Nurses Association has presented some essential elements to have effective preparation. The elements include 1) The definition of delegation, which must be based on the nurse practice act; 2) To review the recommended regulations and laws regarding delegation; 3)

*Address correspondence to this author at the National College of Nursing, The University of Lahore, Lahore, Pakistan.

hafizaanammughal@gmail.com
To identify appropriate disciplinary actions against poor delegation, 4) importance given to such tasks which are difficult or impossible to delegate and might not routinely delegated. 5) to determine the level of supervising for necessary and effective delegation which will help in identification of guidelines that can lead nurses towards lowering risk of delegation [3].

A study was conducted to study the attitude of nurse managers towards the effective nursing delegation among nurses. Results showed that shows the overall mean score was found $(3.1 \pm 0.99)$, which shows that nurses were unsure about their opinions about delegation [4]. Another research study also found similar results where $74.1 \%$ of Nurse Managers were having neutral attitude towards effective delegation among the nurse managers. It simply means that the attitude was not positive towards the effective use of delegation [5].

The findings from a previous study found that there was lack of self-confidence among Nurse Managers towards delegation during their duty. It has been observed that to have a successful delegation the nurse manager's must initially perform a personal character assessment, then need to have positive attitude toward delegation, only then there will be self 
confidence among the nurse managers at each level of the management [6].

Another study conducted among the nurse managers also gives some uncertain results. It shows that the nurse manager's majority responded that they are not sure of their good or bad attitude towards delegation and its effectiveness (66.7\%), of the participants disagreed with the statement, that they do not feel they have time to delegate properly. On another question, about (37.8\%) disagreed that "they would like to delegate more if they were having more confident in delegating". About (64.4\%) of the study participants agreed with the statement, "when they give instruction but still the job remain incomplete, they get upset [7].

Preparedness among nurse managers is very important for their confidence and competency in nursing tasks delivery. It means that the Nurse Managers must adopt the needs for effective delegation. They need to accept that they must learn themselves the competency and then they can help the other junior nurses.

A research study was conducted to assess the attitude and preparedness of delegation among nurse managers. The finding of the study reveals that Nurse Managers to a great extent were familiar with their legal responsibilities and accountabilities during task delegation. There were some points which show the low level of their preparedness such as majority stated that they don't feel that they have sufficient skill to especially to respond to the negative reactions of the delegates during delegation. This might be because of lack of confidence or might be because of low preparation therefore needs the development of skill and confidence among the nurse managers [6].

Another study was conducted at the US emergency department nurse managers. The result findings suggest that $78 \%$ of the emergency nurse managers stated that they were prepared and having excellent or good delegation skills. But still there were $22 \%$ such Nurse Managers who were not prepared and had low score on knowledge of delegation and basic principles of delegation. However, they agreed upon to enhance their delegation skills. It is obvious that nurse manager's skills must be improved and the confidence in delegation must be built. Furthermore it is also important that the Nurse Managers must have awareness regarding staff's legal job definitions. The Managers must also need to understand their job descriptions, and then have sufficient skills to assess the willingness and preparation of the delegates to accept the task being delegated [8].

Results of another regarding to preparedness of delegation indicated some preparedness among the few of the participants. However, a large number of study participants stated that they take too long time to complete their tasks. Among the Nurse Managers about $90 \%$ agreed with the statement that the skills of registered nurses can be utilized better if the delegation is up to standard and effective. Feedback from the staff is very important. Many nurse managers never seek feedback from their staff and therefore did not have well preparation of delegation. It also found that majority nurse managers very less frequently find feedback from the clinical nurses serving in clinical areas. This also lead to a confusion that might the nurse manager fails to explain the task efficiently. Over $45 \%$ of the nurse managers are very much concern (always or sometimes) that staff might think and regards them that they are lazy and ineffective delegators [5].

The finding of a study stress that there are so many registered nurses and nurse managers, who are not clear about the effective delegation. All such nurses want some clear guidelines and understanding of the delegation. On the other hand the employers have more expectations from the nurse graduates of this new era. They believe that new graduates possess knowledge and skills of effective delegation. But when the registered nurses face sick patients with short length of stay, the delegation then they are not well prepared for delegation and need some improvement [1].

A study conducted to assess the attitude and preparedness of registered nurses evaluated a pre and post intervention findings to see the preparedness of nurses to delegation. Supervision skills and professional communication was also evaluated. The effectiveness of intervention was tested through ANOVA test. A significant posttest improvement was found among the participants. A significant improvement was found for the statement if the managers nurses can describe the ways they facilitate through clear communication $(\mathrm{p}=.018)[9]$.

\section{Aims of the Study}

1. To assess the attitude of Nurse Managers toward effective nursing delegation at a public tertiary care hospital Lahore?

2. To assess the nurse manager preparedness toward effective nursing delegation at a public tertiary care hospital Lahore?

\section{Significance of the Study}

This research study will bring some behavior change and skill competency from effective delegation which is more critical for nurse manager to make them able to contemplate their professional nursing activities. Role of Nurse Managers is mainly to delegate if they have no professional knowledge, how to delegate will lead to failure [10]. This research work might bring some work competency among nurse managers in term of understanding nursing delegation. 


\section{METHODS}

\section{Setting}

The current study was conducted in two advanced tertiary care hospitals of Lahore city (Punjab Institute of Cardiology and Services Hospital Lahore). The study was conducted in all inpatient areas such as general medical wards, surgical wards; Specialty wards and the critical care areas of both hospitals.

\section{Research Design}

A quantitative, Cross-sectional descriptive study design was used to assess the attitude and preparedness of effective delegation among the Nurse Managers at tertiary care hospitals. Cross-Sectional Research Studies measures the findings at one point in time simultaneously that is why called as, cross-sectional [11].

\section{Population}

The population of this study was included the nursing managers, nursing supervisors, head nurses and senior charge nurses) working in all concern areas of the selected hospitals.

\section{Sampling}

Convenient sampling technique was used to recruit the required sample size from both the hospitals. A sample of $\mathrm{n}=$ 150 was recruited from the targeted population.

\section{Research Instrument}

A self-administered adopted questionnaire was used. The questionnaire is adopted from "Nurse Manager's Attitudes and Preparedness towards Effective Delegation in Saudi Hospitals" [6]. The questionnaire consists of three vital sections. Section I consists of biodemographic information of the participants which include participants' age, participants' gender, educational background of the study participants, and nursing clinical experience of the participants. Part II consists of the attitude of nurse managers towards delegation. There are 11 question related to attitude with five-point Likert scale Ranging from (5) "Strongly disagree," (4), disagree (3), unsure (2), agree to (1) " strongly agree. Part III of the questionnaire includes 20 statements where 12 statements are about principles of delegation and rights of delegation while remaining are about Nurse Managers' preparedness to delegation.

\section{Data Gathering Procedure}

The questionnaire was distributed to the participants in printed form where they answered the entire question according to their own understanding. A time of about 30 minutes was given to fill the questionnaires. Then the filled questionnaires were collected.

\section{Methods Used to Analyze Data}

Data was analyzed through SPSS version 21. The results are presented in the form of tables and graphs. Descriptive results are presented in averages and percentages. Correlation was found through Pearson correlation test between the attitude and preparedness towards delegation.

\section{Study Timeline}

The data was collected from February, 2018 to April, 2018.

\section{Ethical Consideration}

First of all permission was taken from the research supervisor and the principal of National College of Nursing Lahore. Then a written permission was granted from the head of the selected hospital for the study. The permission was granted from every individual participant. The consent from the participants was taken before distributing the questionnaire. The participants were explained about the purpose, significance and relevant knowledge the want to know regarding this study. Willing participation was encouraged. No one was forced in this research study. Participant can quit the research anytime he/ she feel like. This research was non-maleficent to the participants and to the respected institute.

\section{RESULTS}

\section{Profile of the Respondents}

Respondents were taken from different selected groups of Services and PIC hospital Lahore.

Table 1. Demographic Frequency.

\begin{tabular}{|c|c|c|}
\hline Variables & Number (n) & $\mathbf{\%}$ \\
\hline Gender & & \\
Male & 00 & 00 \\
Female & 150 & 100 \\
\hline Age & 10 & \\
Less than 25 years & 48 & 6.7 \\
26-30 years & 36.0 \\
31-35 years & 56 & 24.0 \\
Above 35 years & & 37.3 \\
\hline Marital Status & 36 & 24.0 \\
Single & 114 & 76.0 \\
Married & 18 & \\
Education & 48 & 32.0 \\
Nursing Diploma & 81 & 54.0 \\
Diploma Plus Specialization & 3 & 2.0 \\
BSN/PRN BSN & & \\
MSN/MPH & 51 & 34.0 \\
\hline Experience & 44 & 29.3 \\
5-10 years & 23 & 15.3 \\
11-15 years & 32 & 21.3 \\
16-20 years & & \\
Above 20 years & &
\end{tabular}


Table 1 presents that there was no male participants while the sample consisted of completely $100 \%$ female study participants. Furthermore, $6.7 \%$ of the study participants were from age less than 25 years, $32 \%$ of the study participants having age between $26-30$ years, $24 \%$ were age group $31-35$ years and $37 \%$ of the study participants were above 35 years of age. $24 \%$ of the respondents were single, while remaining $76 \%$ were married. From the participants, $12 \%$ were only with nursing diploma, $32 \%$ with specialization, $54 \%$ were BSN or post RN BSN and $2 \%$ of the participants were MSN or MPH. Table 1 also reveals that $34 \%$ participants had working experience from 5-10 years, $29.3 \%$ were $11-15$ years of experienced while $15.3 \%$ of the respondents were having experience $15-20$ years and good number $21.3 \%$ had more than 20 years of experience.

Table 2. Attitudes of Nurse Managers towards Delegation.

\begin{tabular}{|c|c|c|c|c|c|c|c|c|c|c|c|}
\hline $\begin{array}{l}\text { S. } \\
\text { No. }\end{array}$ & Statement & \begin{tabular}{|l} 
Str \\
Dis
\end{tabular} & $\begin{array}{l}\text { gly } \\
\text { ree }\end{array}$ & Dis & gree & $\mathrm{Ne}$ & itral & & sree & $\begin{array}{r}\text { Str } \\
\text { A }\end{array}$ & $\begin{array}{l}\text { ngly } \\
\text { ree }\end{array}$ \\
\hline & & $\mathbf{N}$ & $\%$ & $\mathbf{N}$ & $\%$ & $\mathbf{N}$ & $\%$ & $\mathbf{N}$ & $\%$ & $\mathbf{N}$ & $\%$ \\
\hline 1. & $\begin{array}{l}\text { I would delegate more, but the jobs I delegate never seem to get } \\
\text { done the way I want them to be done }\end{array}$ & 12 & 8.0 & 25 & 16.7 & 11 & 7.3 & 89 & 59.3 & 13 & 8.7 \\
\hline 2. & Nurse managers feel they have less time to delegate effectively & 4 & 2.7 & 33 & 22.0 & 26 & 17.3 & 54 & 36.0 & 33 & 22.0 \\
\hline 3. & $\begin{array}{l}\text { Nurse Managers get upset when the job is not done according to } \\
\text { their instructions }\end{array}$ & 14 & 9.3 & 9 & 6.0 & 19 & 12.7 & 52 & 34.7 & 56 & 37.3 \\
\hline 4. & $\begin{array}{c}\text { Managers feel that staffs are not committed and the tasks delegated } \\
\text { would not be completed }\end{array}$ & 00 & 00 & 6 & 4.0 & 37 & 24.7 & 83 & 55.3 & 24 & 16 \\
\hline 5. & $\begin{array}{l}\text { I would delegate more, but if the individual I delegate the task to } \\
\text { does an incompetent job, I'll be severely criticized }\end{array}$ & 7 & 4.7 & 29 & 19.3 & 24 & 16.0 & 60 & 40.0 & 30 & 20.0 \\
\hline 6. & $\begin{array}{l}\text { When Nurse managers delegate, The managers usually find that } \\
\text { often the outcome is not good enough and need to re do it }\end{array}$ & 8 & 5.3 & \begin{tabular}{|l|}
13 \\
\end{tabular} & 8.7 & 26 & \begin{tabular}{|l|}
17.3 \\
\end{tabular} & 81 & 54.0 & 22 & 14.7 \\
\hline 7. & Nurse managers mainly find that delegation is not saving their time & 8 & 5.3 & 45 & 30.0 & 33 & 22.0 & 36 & 24.0 & 28 & 18.7 \\
\hline 8. & $\begin{array}{l}\text { Due to lack of necessary experience, the Nurse managers cannot } \\
\text { delegate as much they want }\end{array}$ & 4 & 2.7 & 24 & 16.0 & 40 & 26.6 & 58 & 38.7 & 24 & 16.0 \\
\hline 9. & Nurse Manager delegate less because of they want perfection & 1 & .7 & 11 & 7.3 & 16 & 10.7 & 91 & 60.7 & 31 & 20.6 \\
\hline 10. & $\begin{array}{l}\text { Nurse Managers can give the routine tasks, but they feel they must } \\
\text { keep the non-routine out }\end{array}$ & 7 & 4.7 & 16 & 10.7 & 13 & 8.7 & 74 & 49.3 & 40 & 26.6 \\
\hline 11. & $\begin{array}{l}\text { Nurse manager would delegate more if they were more confident } \\
\text { in delegating }\end{array}$ & 00 & 00 & 4 & 2.7 & 14 & 9.3 & 89 & 59.3 & 43 & 28.7 \\
\hline
\end{tabular}

The attitude were measured presented in Table 2 . Some mixed responses of agreements and disagreements were found on different statements of attitude towards delegation. $8 \%$ of the study participants strongly disagreed that they would delegate more when the job is not done their way, $16.7 \%$ disagreed with the statement, $7.3 \%$ remained neutral $59.3 \%$ agreed that they will delegate more and $8.7 \%$ strongly agreed to the statement. $2.7 \%$ stated with strongly disagreement that they have no time to delegate, $22 \%$ participants disagreed with this, $17.3 \%$ remained neutral, $36 \%$ agreed to the statement that they don't feel they have time to delegate and $22 \%$ strongly agreed. On a statement that when the nurse managers give delegation and the job is not done right, they get frustrated, $9.3 \%$ strongly disagreed, $6 \%$ disagreed, $12.7 \%$ were neutral, $34.7 \%$ agreed to the statement and more than $37.3 \%$ strongly agreed to the question. On a question that any job they delegate will not be done because of the staff not commitment, $4 \%$ disagreed, $24.7 \%$ were neutral, $55.3 \%$ participants agreed to the statement, and $16 \%$ strongly agreed that they feel lack of commitment from the nurses subordinates. On question to delegate to incompetent staff leads to more criticism the responses were as below, $4.7 \%$ strongly disagreed, $19.3 \%$ disagreed, $16 \%$ neutral, $40 \%$ agreed to the above statement and $20 \%$ strongly agreed.
When I delegate a job, I often find that the outcome is such that I end up redoing the job myself $5.3 \%$ strongly disagreed, $8.7 \%$ disagreed, 17.3 neutral, $54 \%$ agreed and $14.7 \%$ strongly agreed. To a question that delegate hardly saves any time $5.3 \%$ strongly disagreed, $30 \%$ participants disagreed, $22 \%$ were neutral, $24 \%$ participants agreed and $18.7 \%$. strongly agreed to the statement. To a question that nurse managers can't delegate as much as they would like because their subordinates lack the necessary experience $2.7 \%$ strongly disagreed to this, $16 \%$ disagreed, $26.6 \%$ remained neutral, $38.7 \%$ agreed with it and $16 \%$ strongly agreed. To another question that the nurse managers would delegate more but they are not pretty much a perfectionist, $0.7 \%$ participants strongly disagreed, $7.3 \%$ disagreed to this, $10.7 \%$ remained neutral about it, $60.7 \%$ agreed to the statement and $20.6 \%$ strongly agreed. When they were asked if they can give subordinates the routine tasks, where $4.7 \%$ participants strongly disagreed, $10.7 \%$ disagreed, $8.7 \%$ remained neutral, $49.3 \%$ agreed to the statement and $26.6 \%$ strongly agreed. Another statement was asked I (Nurse managers) would delegate more if I (Nurse managers) were more confident in delegating $0 \%$ Strongly disagreed, $2.7 \%$ disagreed, $9.3 \%$ neutral, $59.3 \%$ agreed to this and $28.7 \%$ strongly agreed with this statement. 
Table 3. Overall Attitude Score.

\begin{tabular}{|c|c|c|c|c|}
\hline \multicolumn{5}{|c|}{ Attitude Level } \\
\hline & Frequency & Percent & Valid Percent & Cumulative Percent \\
\hline $\begin{array}{c}\text { Negative attitude (Less than 35 } \\
\text { score/55) }\end{array}$ & 18 & 12.0 & 12.0 & 12.0 \\
\hline $\begin{array}{c}\text { Possitive Attitude (35 or above } \\
\text { score/55) }\end{array}$ & 132 & 88.0 & 88.0 & 100.0 \\
\hline Total & 150 & 100.0 & 100.0 & \\
\hline
\end{tabular}

Table 3 reveals that majority of the participants, $88 \%$ were having positive attitude towards delegation that scored 35 or above on a scale of 55 total score, while $12 \%$ had negative attitude that scored below 35 on attitude scale of 55 .

Table 4a. Frequency and Percentages of the Preparedness Sub Scale 1.

\begin{tabular}{|c|c|c|c|c|c|c|c|c|c|c|c|}
\hline \begin{tabular}{|l|} 
S. \\
No.
\end{tabular} & Statement & & $\begin{array}{l}\text { ngly } \\
\text { gree }\end{array}$ & Disa & ee & eu & l & & ree & & \\
\hline & Subscale 1 & $\mathbf{N}$ & $\%$ & $\mathbf{N}$ & $\%$ & $\mathbf{N}$ & $\%$ & $\mathbf{N}$ & $\%$ & $\mathbf{N}$ & $\%$ \\
\hline 1. & I take into account staff 's individual skills prior to delegation & 3 & 2.0 & 14 & 9.3 & 15 & 10.0 & 46 & 30.7 & 72 & 48.0 \\
\hline 2. & I give staff feedback following delegation (e.g. praise) & 1 & .7 & 18 & 12.0 & 29 & 19.3 & 47 & 31.3 & 55 & 36.7 \\
\hline 3. & $\begin{array}{l}\text { I seek feedback from staff on whether you have explained the task } \\
\text { sufficiently }\end{array}$ & 3 & 2.0 & 26 & 17.3 & 25 & 16.7 & 45 & 30.0 & 51 & 34.0 \\
\hline 4. & I seek feedback from staff to improve your delegation skills & 3 & 2.0 & 17 & 11.3 & 20 & 13.3 & 39 & 26.0 & 71 & 47.4 \\
\hline 5. & I find you spend a lot of time on jobs others could do & 12 & 8.0 & 10 & 6.7 & 44 & 29.3 & 41 & 27.3 & 43 & 28.7 \\
\hline 6. & I think you give up power or lose respect because of delegation & 21 & 14.0 & 32 & 21.3 & 50 & 33.3 & 41 & 27.3 & 6 & 4.1 \\
\hline 7. & I concerned that staff finds me lazy for delegating tasks & 63 & 42.0 & 24 & 16.0 & 28 & 18.7 & 29 & 19.3 & 6 & 4.0 \\
\hline 8. & In delegation, I make clear who is to do the task & 3 & 2.0 & 9 & 6.0 & 10 & 6.7 & 27 & 18.0 & 101 & 67.3 \\
\hline 9. & In delegation, I make clear when to do the task & 00 & 00 & 1 & .7 & 17 & 11.3 & 15 & 10.0 & 117 & 78.0 \\
\hline 10. & In delegation, I make clear where to do the task & 1 & .7 & 3 & 2.0 & 13 & 8.7 & 16 & 10.6 & 117 & 78.0 \\
\hline 11. & In delegation, I make clear why to do the task & 1 & .7 & 3 & 2.0 & 12 & 8.0 & 22 & 14.7 & 112 & 74.6 \\
\hline 12. & In delegation, I make clear how to do the task & 00 & 00 & 2 & 1.3 & 13 & 8.7 & 17 & 11.3 & 118 & 78.7 \\
\hline
\end{tabular}

Table 4b. Frequency and Percentages of the Preparedness Sub Scale 2.

\begin{tabular}{|c|c|c|c|c|c|c|c|c|c|c|c|}
\hline $\begin{array}{c}\text { S. } \\
\text { No. }\end{array}$ & $\begin{array}{l}\text { Strongly } \\
\text { Disagree }\end{array}$ & \multicolumn{2}{|c|}{ Disagree } & \multicolumn{2}{|c|}{ Neutral } & \multicolumn{3}{|c|}{$\begin{array}{c}\text { Agree } \\
\text { Strongly } \\
\text { Agree }\end{array}$} \\
\hline & Subscale 2 & $\mathbf{N}$ & $\mathbf{\%}$ & $\mathbf{N}$ & $\mathbf{\%}$ & $\mathbf{N}$ & $\mathbf{\%}$ & $\mathbf{N}$ & $\mathbf{\%}$ & $\mathbf{N}$ & $\%$ \\
\hline 1. & $\begin{array}{c}\text { Nursing staff' skills could be better utilized with more effective } \\
\text { delegation }\end{array}$ & 2 & 1.3 & 4 & 2.7 & 2 & 1.3 & 52 & 34.7 & 90 & 60.0 \\
\hline 2. & Delegated duties are documented & 00 & 00 & 00 & 00 & 17 & 11.3 & 65 & 43.3 & 68 & 45.4 \\
\hline 3. & $\begin{array}{c}\text { Documentation of delegated duty helps employee to know exactly } \\
\text { what is expected and how the task will be evaluated }\end{array}$ & 00 & 00 & 1 & .7 & 7 & 4.7 & 58 & 38.6 & 84 & 56.0 \\
\hline 4. & $\begin{array}{c}\text { I think I have received sufficient preparation to delegate through } \\
\text { my education or at work }\end{array}$ & 2 & 1.3 & 17 & 11.3 & 73 & 48.7 & 44 & 29.4 & 14 & 9.3 \\
\hline 5. & $\begin{array}{c}\text { Effective delegation improves staff development and satisfaction, } \\
\text { which results in better patient care and patient satisfaction }\end{array}$ & 1 & .7 & 00 & 00 & 19 & 12.6 & 31 & 20.7 & 99 & 66.0 \\
\hline 6. & I find it clear which tasks can be delegated to nursing staff & 00 & 00 & 00 & 00 & 15 & 10.0 & 80 & 53.3 & 55 & 36.7 \\
\hline 7. & $\begin{array}{c}\text { I think I have sufficient skills to face staff's negative reaction when } \\
\text { delegating tasks }\end{array}$ & 00 & 00 & 2 & 1.3 & 19 & 12.7 & 91 & 60.7 & 38 & 25.3 \\
\hline 8. & I am familiar with my legal responsibilities when delegating & 00 & 00 & 1 & .7 & 10 & 6.7 & 49 & 32.7 & 90 & 60.0 \\
\hline
\end{tabular}

Table 4a shows to a statement whether nurse managers consider it important that staff should be skill full to have effective delegation, $2 \%$ of the study participants strongly disagreed that they, 9.3\% disagreed with the statement, $10 \%$ remained neutral $30.7 \%$ agreed and $48 \%$ strongly agreed to the statement. To another question whether nurse managers give staff feedback following delegation, $.7 \%$ stated with strongly disagreement, $12 \%$ participants disagreed with this, $19.3 \%$ remained neutral, $31.3 \%$ agreed to the statement and $36.7 \%$ strongly agreed. On a statement that Nurse Managers try to get feedback from their area staff nurses about the task been explained effectively or not, $2 \%$ strongly disagreed, 
$17.3 \%$ disagreed, $16.7 \%$ were neutral, $30 \%$ agreed to the statement and more than $34 \%$ strongly agreed to the question. On a question that nurse managers seek feedback from the subordinate staff nurses to improve self and nurses' delegation skills, $2 \%$ Strongly disagreed, $11.3 \%$ disagreed, $13.3 \%$ were neutral, $26 \%$ participants agreed to the statement, and $47.4 \%$ strongly agreed. On question statement that Nurse Managers find that junior and low experienced nurses spend more time on jobs as compare to experienced one, $8 \%$ strongly disagreed, $6.7 \%$ disagreed, $29.3 \%$ neutral, $27.3 \%$ agreed to the above statement and $28.7 \%$ strongly agreed. They were asked if the nurse managers feels like losing respect due to delegating tasks $14 \%$ strongly disagreed, $21.3 \%$ disagreed, 33.3 neutral, $27.3 \%$ agreed and $4.1 \%$ strongly agreed. To a question that nurse managers feel it that staff nurses think them lazy because they delegate job and not doing self, $42 \%$ strongly disagreed, $16 \%$ participants disagreed, $18.7 \%$ were neutral, $19.3 \%$ participants agreed and $4 \%$ strongly agreed to the statement. To a question that while delegating, nurse managers clearly allocating tasks, $2 \%$ strongly disagreed to this, $6 \%$ disagreed, $6.7 \%$ remained neutral, $18 \%$ agreed with it and $67.3 \%$ strongly agreed. To another question that In delegation, Deadlines and timelines are clearly explained, $0.0 \%$ participants strongly disagreed, $0.7 \%$ disagreed to this, $11.3 \%$ remained neutral about it, $10 \%$ agreed to the statement and $78 \%$ strongly agreed. When they were asked In delegation, The area and procedures are clearly guided by the nurse managers, where $0.7 \%$ participants strongly disagreed, $2 \%$ disagreed, $8.7 \%$ remained neutral, $10.6 \%$ agreed to the statement and $78 \%$ strongly agreed. Another statement was asked In delegation, the nurse managers clearly explain the reason of doing that task, where $0.7 \%$ Strongly disagreed, $2 \%$ disagreed, $8 \%$ neutral, $14.7 \%$ agreed to this and $74.6 \%$ strongly agreed with this statement. To another question that in delegation, managers make clear instructions about the procedure of doing task, $0.0 \%$ participants strongly disagreed, $1.3 \%$ disagreed to this, $8.7 \%$ remained neutral about it, $11.3 \%$ agreed to the statement and $78.7 \%$ strongly agreed.

Table 4b findings reveal that to a statement that if nurse manager's delegate effectively they can effectively utilize the skill of nurses, $1.3 \%$ of the study participants strongly disagreed that they, $2.7 \%$ disagreed with the statement, $1.3 \%$ remained neutral $34.7 \%$ agreed and $60 \%$ strongly agreed to the statement. To another question whether Delegated duties are documented, $0.00 \%$ stated with strongly disagreement, $0.00 \%$ participants disagreed with this, $11.3 \%$ remained neutral, $43.3 \%$ agreed to the statement and $45.4 \%$ strongly agreed. On a statement that if the delegation is documented, it guides about the needs of delegation and the procedure of tasks, $0.0 \%$ strongly disagreed, $0.7 \%$ disagreed, $4.7 \%$ were neutral, $38.6 \%$ agreed to the statement and more than $56 \%$ strongly agreed to the question. On a question that feedback of staff is used to help improve their delegation outcome, $11.3 \%$ disagreed, $48.7 \%$ were neutral, $29.3 \%$ participants agreed to the statement, and $9.3 \%$ strongly agreed. On question statement that nurse managers think they have received sufficient preparation to delegate through education or training, $0.7 \%$ strongly disagreed, $0.00 \%$ disagreed, $12.6 \%$ neutral, $20.7 \%$ agreed to the above statement and $66 \%$ strongly agreed. They were asked if effective delegation improves staff development and satisfaction $0 \%$ strongly disagreed, $0 \%$ disagreed, $10 \%$ neutral, $53.3 \%$ agreed and $36.7 \%$ strongly agreed. To a question that I find it clear which tasks can be delegated to nursing staff, $0.00 \%$ strongly disagreed, $1.3 \%$ participants disagreed, $12.7 \%$ were neutral, $60.7 \%$ participants agreed and $25.3 \%$ strongly agreed to the statement.

\section{DISCUSSION}

Findings of my study are that $2.7 \%$ stated with strongly disagreement that they have no time to delegate, $22 \%$ participants disagreed with this, $17 \%$ remained neutral, $36 \%$ agreed to the statement that they don't feel they have time to delegate and 22\% strongly agreed. Furthermore, another statement was asked I (Nurse managers) would use the delegation process more often if they were more confident, $0 \%$ Strongly disagreed, $2.7 \%$ disagreed, $9.3 \%$ neutral, $59.3 \%$ agreed to this and $28.7 \%$ strongly agreed with this statement.

In a previous study, a large percentage $(66.7 \%)$, of the participants were not of the agreement to a statement, that nurse managers do not feel they have enough time to delegate properly. On another question, about (37.8\%) disagreed that they would delegate more if having more encouragement and appreciation. About (64.4\%) of the study participants gave an agreement to a statement, that they get upset when the delegated task is not done and is incomplete after a thorough delegation instructions [7].

The results of this study reveals that majority of the participants, $88 \%$ were having positive attitude towards delegation who scored 35 or above on a scale of 55 total score, while $12 \%$ had negative attitude who scored below 35 on attitude scale of 55 .

Results of a previous study, showed that the overall mean score was found $(3.1 \pm 0.99)$, which shows that nurses were unsure about their opinions about delegation [4]. Another research study also found similar results where $74.1 \%$ of Nurse Managers were having neutral attitude towards effective delegation among the nurse managers. It simply means that the attitude was not positive towards the effective use of delegation [5].

Another study indicate that there was a relatively positive attitude towards delegation among the participants. Still some responses were negative and needs improvement. If the job is 
not done right, it makes the nurse manager upset and unhappy. Some participants had negative attitude about others and believed that if they do a committed job with good delegation, the delegators will all times delegate themselves and will not do much of them. Participants with low experienced believed that their delegation would be improved after they are encouraged and given confidence (p.002) as against with registered nurses with more experience [5].

The results of this study indicate that $82.67 \%$ participants had good preparedness, who scored 75 or above in a total of 100 score, while remaining $17.3 \%$ scored less than 75 and had poor preparedness.

In a previous study, majority of the study participants stated that they don't feel that they have sufficient skill to especially to respond to the negative reactions of the delegates during delegation. This might be because of lack of confidence or might be because of low preparation therefore needs the development of skill and confidence among the nurse managers [6]. The result findings of a previous study suggest that $78 \%$ of the emergency nurse managers stated that they were prepared and having excellent or good delegation skills. But still there were 22\% such Nurse Managers who were not prepared and had low score on knowledge of delegation and basic principles of delegation [8].

It was found in study, that majority of the nurse managers very less often seek feedback from the staff nurses on whether the delegation task is explained correct or incorrect. Over 45\% nurse managers are very much concerned that the staff nurses and subordinates may regards them lazy because they are delegating tasks and not doing themselves [5].

\section{LIMITATIONS}

- The sample size is low, 150 which are not sufficient to generalize the findings to a larger population.

- The duration of the study was short therefore no prospective events or progress could be seen.

- Convenient sampling technique was used which may have some biasness.

\section{CONCLUSION}

The overall findings of this current study suggest a positive attitude of delegation among the nurse managers and other senior nurses. To have a successful patients care outcomes and patients satisfaction, there is need to improve staff development and satisfaction with effective delegation. For more effective and satisfactory delegation nurse managers are advised to improve the skills and knowledge of subordinate nurses and the needed learning opportunities to boost their confidence and competency of doing skills with minimum guidance. As a result of current study it is believed that nurse managers need to have access to the education based on knowledge, attitude and practice of nursing delegation. Thus there is need that the policy makers and top nursing management include nursing delegation among the managers as continuous nursing education program course. Furthermore, nurse managers are supposed to follow the recommended training and program to ensure the quality recommended delegation among the subordinate and junior nursing staff following the essential guidelines to ensure effective.

\section{CONFLICT OF INTEREST}

Declared none.

\section{ACKNOWLEDGEMENTS}

I am highly thankful to Allah, for giving me the strength and knowledge to carry out this research work. Without Allah's blessings and providence it would not be possible to complete this research project successfully.

I would acknowledge and like to express special thanks to my teacher, my supervisor (Sir Afsar Ali) as well as our principle (Mam Naseem Roman) who gave me the golden opportunity to do this wonderful project on the topic. This also helped me a lot in doing of Research. I came to know about so many new things I am really thankful to them.

Secondly, I would also like to thank my parents and friends who helped me a lot in finalizing this project within the limited time frame.

\section{REFERENCES}

[1] Ruff VA. Delegation Skills: Essential to the Contemporary Nurse. Thesis. USA: Sophia: St. Catherine University 2011.

[2] Villeneuve M, MacDonald J. Toward 2020: Visions for nursing setting the stage for the future. Can Nurse 2006; 102(5): 22.

[3] O'keefe C. The authority for certain clinical tasks performed by unlicensed patient care technicians and LPNs/LVNs in the hemodialysis setting: A review. Nephrol Nurs J 2014; 41(3): 247.

[4] Zeighami MS, Asgharzadeh HS, Nuhegar AA. Attitude of nursing managers about delegation in Karaj social security clinics and hospitals 2010. Modern Care J 2013; 9(3): 273-8.

[5] Kærnested B, Bragadóttir H. Delegation of registered nurses revisited: Attitudes towards delegation and preparedness to delegate effectively. Nord J Nurs Res 2012; 32(1): 10-5. DOI: $10.1177 / 010740831203200103$

[6] Salem OA Hakami AA. Nurse Manager's attitudes and preparedness towards effective delegation in Saudi Hospitals. Health Sci J 2016; 10(3): 1-10.

[7] Gassas RS, Mahran SM, Banjar HI. Nurse managers' attitude and competency towards delegation in Jeddah City. Am J Nurs 
2017; 6(2): 72-9. DOI: 10.11648/j.ajns.20170602.11

[8] Whitehead DK, Weiss SA, Tappen RM. Essentials of Nursing Leadership and Management. $5^{\text {th }}$ ed. Philadelphia, United States: FA Davis Company 2010.

[9] Wagner EA. Improving patient care outcomes through better delegation-communication among nurses and assistive personnel. J Nurs Care Qual 2018; 33(2): 187-93.

DOI: $10.1097 / \mathrm{NCQ} .0000000000000282$
[10] Piscotty RJ, Kalisch B, Gracey-Thomas A. Impact of healthcare information technology on nursing practice. J Nurs Scholarsh 2015; 47(4): 287-93. DOI: 10.1111/jnu.12138

[11] Polit D, Beck CT. Planning a nursing study. In; Nursing Research: Generating and Assessing Evidence for Nursing Practice. $9^{\text {th }}$ ed. Philadelphia, PA: Lippincott Williams \& Wilkins 2012; pp. 174-99. 